\title{
Ultra fast frequency independent instantaneous power factor detector
}

Safaa S. Omran, Ali. Sh. Al-Khalid, Amer Atta Yaseen

Middle Technical University, Electrical Engineering Technical College, Iraq

\begin{tabular}{l}
\hline Article Info \\
\hline Article history: \\
Received Apr 5, 2019 \\
Revised Jun 28, 2019 \\
Accepted Jul 22, 2019 \\
\hline
\end{tabular}

Keywords:

Lead lag Indicator

Microcontroller

Power factor detector

\begin{abstract}
Many schemes were attempted to lessenthe time taken for measuring the power factor of a linear load. This paper suggests taking advantage of a previous paper where only two samples of the voltage and current were adequate to have a very fast calculation method of the power factor. That scheme used a phase locked loop (PLL) as a frequency multiplier scheme to acquire two progressive samples of the voltage and current which are concurrent. The time elapsed for measurement was the reciprocal of the PLL sampling frequency; no further scheme was reported after that to claim a faster method. This paper gets use of that work to get two progressive samples of voltage and current separated by a short time. The scheme is frequency independent with an indication for lead lag. All the operations are executed by a PIC microcontroller rather than a computer with few support circuits. The output will be shown either in digital or analogue (DC) form. The percentage of error depends mainly on the resolution (number of bits) for both the ADC and DAC used.
\end{abstract}

Copyright $(2019$ Institute of Advanced Engineering and Science. All rights reserved.

\section{Corresponding Author:}

Safaa S Omran, Middle Technical University, Electrical Engineering Technical College, Iraq.

E-mail: Omran_safaa@ymail.com

\section{INTRODUCTION}

The power factor measurement is important issue and there is always a need of a device which can directly give a linear output de signal proportional to the power factor magnitude.

Many attempts were strived to measure the power factor of a power line frequency load [1-9]. All of these methods took at least one cycle of the power inputs to detect the power factor. A half a cycle of the input power line frequency measurement time was reported in [10-14]. The execution time was diminished to a quarter a cycle in [15]. The time was further reduced to three consecutive samples by [16]. This was developed later by Al-Khalid and Omran to reduce the number of samples needed to only two [17]. Using microcontroller in measuring the power factor was illustrated in [18-20].

This paper intends to get use of the work in [17] by letting a microcontroller rather than a computer to accomplish frequency independent detection. In this case the scheme will be appropriate for portable usage putting in mind that the result will be given in digital and analogue (dc) form. So, the detector will be suitable for on line measurement or using a d.c voltmeter. The scheme is intended for undistorted signal (no harmonics are present). The transient response time of the proposed method is ultra-fast and will be limited only by the lowest sampling time of the ADC module and the measured value will present the instantaneous magnitude of power factor with an indication to whether the power factor is lagging or leading. 


\section{THEORY OF CALCULATION}

Relating to Figure 1, the two voltage samples are,

$$
\begin{aligned}
& v 1=V m \sin \alpha \\
& v 2=V m \sin \beta=V m \sin (\alpha+\psi) \\
& v 2=V m(\sin \alpha \cos \psi+\cos \alpha \sin \psi)
\end{aligned}
$$

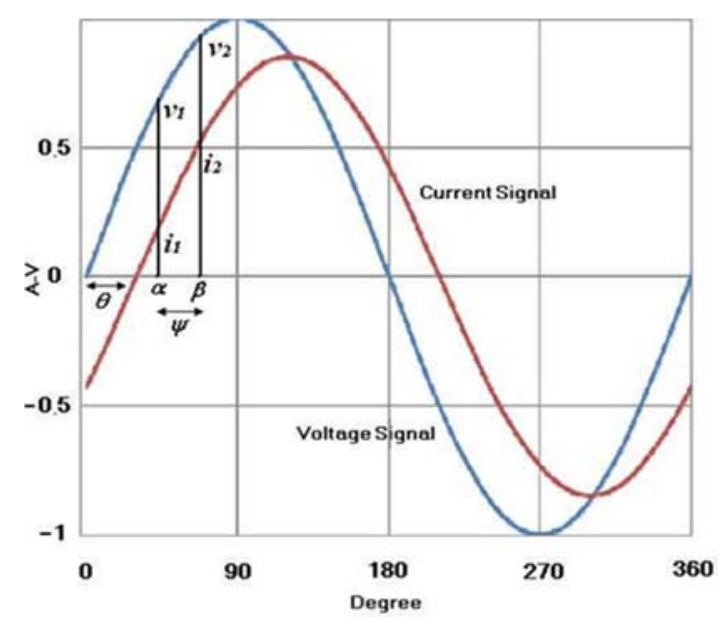

Figure 1. Voltage and current samples

$$
\begin{aligned}
& \frac{v 2}{v 1}=\frac{V m(\sin \alpha \cos \psi+\cos \alpha \sin \psi)}{V m \sin \alpha} \\
& \cot \alpha=\frac{\frac{v 2}{v 1}-\cos \psi}{\sin \psi}
\end{aligned}
$$

The two current samples $i 1$ and $i 2$ can be written as follows:

$i 1=I m \sin (\alpha+\theta)$

$i 2=\operatorname{Im} \sin ((\alpha+\theta)+\psi)$

$i 2=\operatorname{Im}[\sin (\alpha+\theta) \cos \psi+\cos (\alpha+\theta) \sin \psi]$

Where $\theta$ is the phase angle between the voltage and the current signals.

$$
\begin{aligned}
& \text { Now, } \frac{i 2}{i 1}=\cos \psi+\cot (\alpha+\theta) \sin \psi \\
& \text { Hence, } \cot (\alpha+\theta)=\frac{\frac{i 2}{i 1}-\cos \psi}{\sin \psi} \\
& \text { Let } \alpha+\theta=\gamma \\
& \text { Hence, } \theta=\gamma-\alpha \\
& \text { Now, } \cot \theta=\cot (\gamma-\alpha)=\frac{1+\cot \alpha \cot \gamma}{\cot \alpha-\cot \gamma} \\
& \cot \theta=\frac{\left(\frac{\frac{v 2}{v 1}-\cos \psi}{\sin \psi}\right)\left(\frac{\frac{i 2}{i 1}-\cos \psi}{\sin \psi}\right)}{\frac{v 2}{v 1}-\cos \psi} \frac{\frac{i 2}{\sin \psi}-\cos \psi}{\sin \psi} \\
& \cot \theta=\frac{1+\frac{v 2 i 2}{v 1 i 1}-\left(\frac{v 2}{v 1}+\frac{i 2}{i 1}\right) \cos \psi}{\left(\frac{v 2}{v 1}-\frac{i 2}{i 1}\right) \sin \psi} \\
& \text { Let } K 1=\cot \theta \\
& \text { So, } K 1=\frac{\cos \theta}{\sqrt{1-\cos ^{2} \theta}}
\end{aligned}
$$


Squaring both sides of (8) and solving for the power factor $(\cos \theta)$,

$$
\cos \theta=\frac{K 1}{\sqrt{1+(K 1)^{2}}}
$$

where

$$
K 1=\frac{I+\frac{v 2 i 2}{v 1 i 1}-\left(\frac{v 2}{v 1}+\frac{i 2}{i 1}\right) \cos \psi}{\left(\frac{v 2}{v 1}-\frac{i 2}{i 1}\right) \sin \psi}
$$

$\Psi$ can be calculated from (1) and (2) as follows

$$
\begin{aligned}
& \alpha=\sin ^{-1}\left(\frac{v 1}{V m}\right) \\
& \beta=\sin ^{-1}\left(\frac{v 2}{V m}\right) \\
& \psi=\beta-\alpha \\
& \text { Hence, } \psi=\sin ^{-1}\left(\frac{v 2}{V m}\right)-\sin ^{-1}\left(\frac{v 1}{V m}\right)
\end{aligned}
$$

With a constant value $\mathrm{Vm}$, the power factor can be calculated depending only on samples $v 1, v 2$ and their corresponding current samples $i 1, i 2$ and the proposed system will be updated if any change occures in $V m$ value to prevent any possible error in calculated power factor as will be described later. If the value of $v 1$ or $i 1$ was taken at zero crossing (their value is zero) in this case the value of $K 1$ is undefined.

When $v 1=0$

$$
\begin{aligned}
& v 1=V m \sin \alpha, \text { hence }, \alpha=0 \text { or } \pi \\
& i 1=I m \sin (\alpha+\theta)=I m \sin \theta \\
& i 2=I m \sin \theta \cos \psi+I m \cos \theta \sin \psi
\end{aligned}
$$

From (12) \& (13)

$$
\begin{aligned}
& \frac{i 2}{i 1}=\cos \psi+\cot \theta \sin \psi \\
& \cot \theta=\frac{\frac{i 2}{i 1}-\cos \psi}{\sin \psi} \\
& \text { Assume, } K 2=\frac{\frac{i 2}{i 1}-\cos \psi}{\sin \psi}
\end{aligned}
$$

Using the same procedure used previously in obtaining (9), we get that,

$$
\cos \theta=\frac{K 2}{\sqrt{1+(K 2)^{2}}}
$$

It is clear from (15) that the power factor is calculated in this case from only current samples.

When $\mathrm{i1}=0$

$$
\begin{aligned}
& i 1=\operatorname{Im} \sin (\alpha+\theta)=0 \\
& \text { Hence, } \theta=-\alpha \text {, or } \theta=\pi-\alpha, \text { and } \\
& \cot \theta=\frac{\cos \psi-\frac{v 2}{v 1}}{\sin \psi} \\
& \text { Assume, } K 3=\frac{\cos \psi-\frac{v 2}{v 1}}{\sin \psi}
\end{aligned}
$$

Now, doing the same sequence used in (9) for finding the power factor $(\cos \theta)$,

$$
\cos \theta=\frac{K 3}{\sqrt{1+(K 3)^{2}}}
$$

It is clear from (17) that the power factor is calculated in this case from only voltage samples. 


\section{HARDWARE IMPLEMENTATION}

The system block and circuit diagram are shown in Figure 2 and Figure 3 respectively. The microcontroller used is PIC18F45. Full description of the required conversion time was reported in [20]. Two non inverting operational amplifiers, level shifters are used to convert a positive to negative signal into a range suitable for the $\mathrm{ADC}$.

Peak detector is used when we have a rapidly changing AC input signal, and we want to obtain the peak voltage that the signal reaches. The peak detector is used with precision full wave circuit in order to detect both the positive and negative peak value of the AC voltage source. Also, it is possible to give a lead lag indicating signal by using the D flip-flop function that implemented within the microcontroller program. Where in cases of leading angles gives positive pf and lagging angles negative pf.

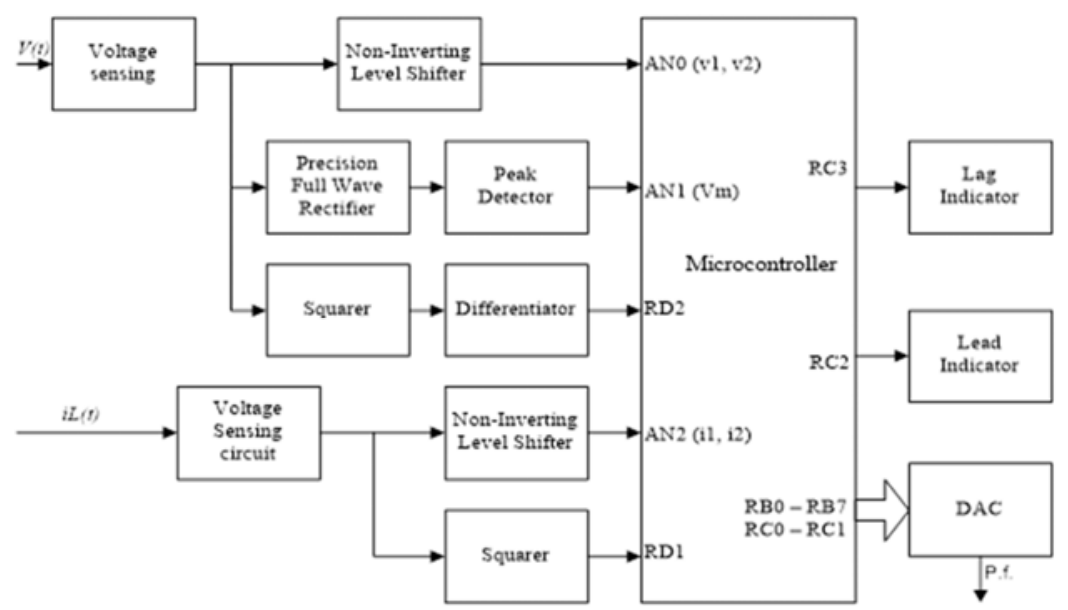

Figure 2. System block diagram

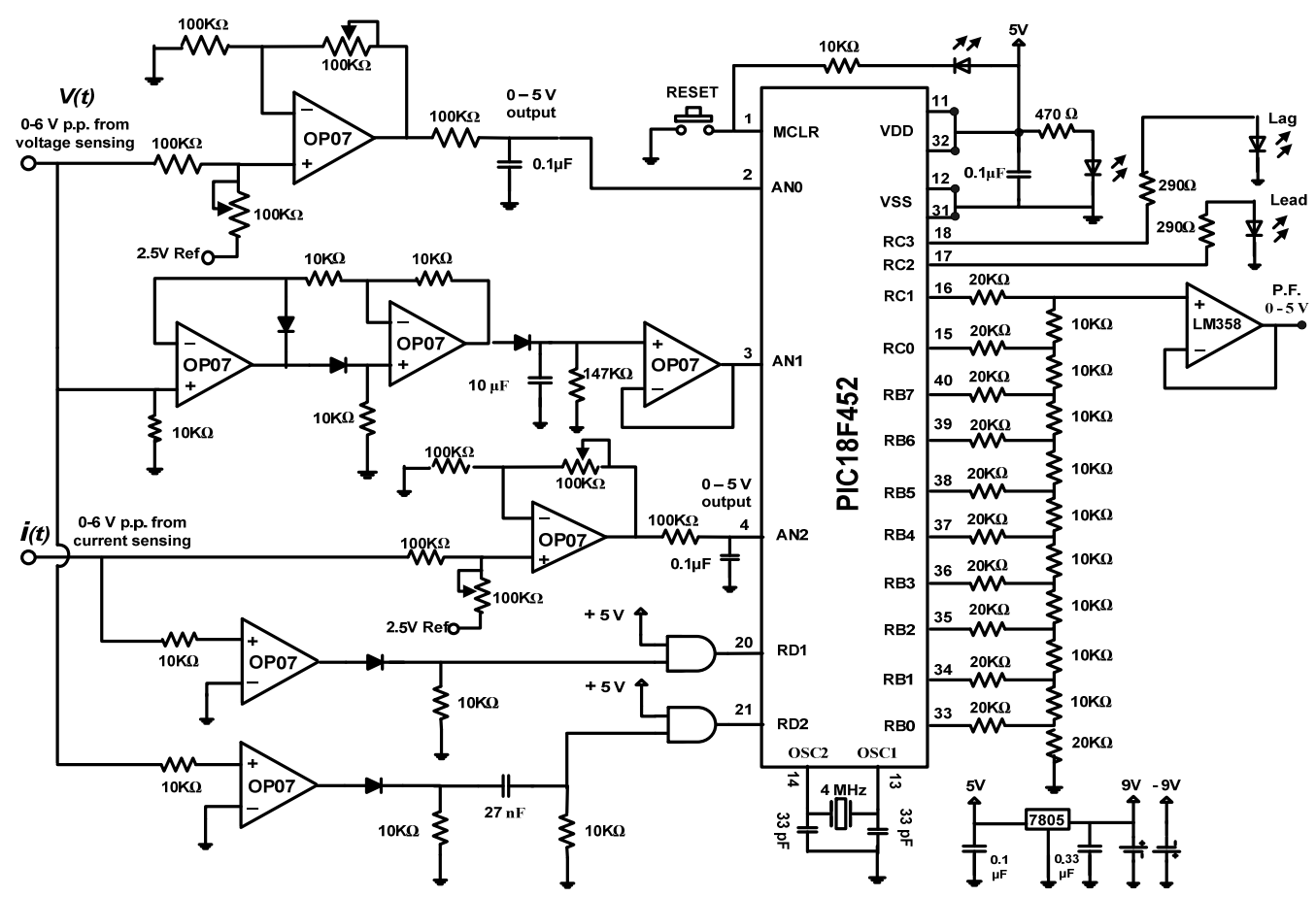

Figure 3. System circuit diagram 


\section{SOFTWARE IMPLEMENTATION}

Figure 4 shows the flowchart for the calculation of power factor. This program was written in $\mathrm{C}$ Language, using the mikro $\mathrm{C}$ compiler (mikroElektronica). The power factor $\mathrm{C}$ program, contains the functions that initializes the microcontroller, acquires the two samples from the input voltage signal and the corresponding two current samples, the input from peak detector, calculating the value of $\psi$ using (11) and calculating the value of $\mathrm{K} 1, \mathrm{~K} 2$ or $\mathrm{K} 3$ using one of the three cases according to $(10,14$, and 16). The range of PIC18F452 ADC channels is always positive so that we need to recognize the negative values of voltage and current samples. This accomplished by changing to the negative sign of any values less than 512 . The final value of power factor achieved using one of three $(9,15$, and 17).

\section{EXPERIMENTAL RESULTS}

An Ultra Fast Frequency Independent Instantaneous Power Factor Detector is implemented as proposed in previos sections. It is clear from the results shown in Table 1, that the theoretical and the practical results are very close. The difference between the theoretical and the practical results are because of the limitation of the ADC and the resolution of the 10-bits DAC used in the microcontroller. Figure 5 illustrates the frequency independent facility of the designed detector. As shown the performance of the detector is unaffected by the frequency of the input voltage and current. In comparision with other papers speed was not put into account in [18], while special care is realized to adjust the output of the PLL concerning maximum expected peak of the input voltage (current) and to be in phase with the input [20]. Nothing was mentionsd about speed in [21-23].

The first sample it was neglected if it occurred to be of zero value as explained before. Other sample values can be tackled remembering that a 10-bit ADC is available with full range input of zero to $+5 \mathrm{v}$.

Table 1. Test results

\begin{tabular}{|c|c|c|c|c|c|c|}
\hline $\begin{array}{c}\text { Phase } \\
\text { shift }(\theta)\end{array}$ & $\begin{array}{l}\text { Theoretical power } \\
\text { factor }\end{array}$ & $\begin{array}{l}\text { Detector output } \\
(\mathrm{Vdc})\end{array}$ & $\begin{array}{l}\text { Detector output } \\
\text { (P.F) }\end{array}$ & $\begin{array}{l}\text { Status of } \\
\mathrm{RC} 2\end{array}$ & $\begin{array}{l}\text { Status of } \\
\text { RC3 }\end{array}$ & Error \% \\
\hline-90 & 0 Lagging & 0 & 0 & $0 \mathrm{v}$ & $+5 \mathrm{v}$ & 0 \\
\hline-80 & 0.1735 Lagging & 0.8675 & 0.1736 & $0 \mathrm{v}$ & $+5 \mathrm{v}$ & -0.085 \\
\hline-60 & 0.5 Lagging & 2.5015 & 0.5003 & $0 \mathrm{v}$ & $+5 \mathrm{v}$ & 0.06 \\
\hline-40 & 0.7659 Lagging & 3.831 & 0.7662 & $0 \mathrm{v}$ & $+5 v$ & 0.02 \\
\hline-20 & 0.9396 Lagging & 4.697 & 0.9394 & $0 \mathrm{v}$ & $+5 \mathrm{v}$ & -0.031 \\
\hline 0 & 1 & 5 & 1 & $0 \mathrm{v}$ & $0 \mathrm{v}$ & 0 \\
\hline 20 & 0.9396 Leading & 4.6975 & 0.9395 & $+5 \mathrm{v}$ & $0 \mathrm{v}$ & -0.02 \\
\hline 40 & 0.7659 Leading & 3.8285 & 0.7657 & $+5 \mathrm{v}$ & $0 \mathrm{v}$ & -0.045 \\
\hline 60 & 0.5 Leading & 2.502 & 0.5004 & $+5 \mathrm{v}$ & $0 \mathrm{v}$ & 0.08 \\
\hline 80 & 0.1735 Leading & 0.8685 & 0.1736 & $+5 \mathrm{v}$ & $0 \mathrm{v}$ & 0.03 \\
\hline 90 & 0 Leading & 0 & 0 & $+5 v$ & $0 \mathrm{v}$ & 0 \\
\hline
\end{tabular}

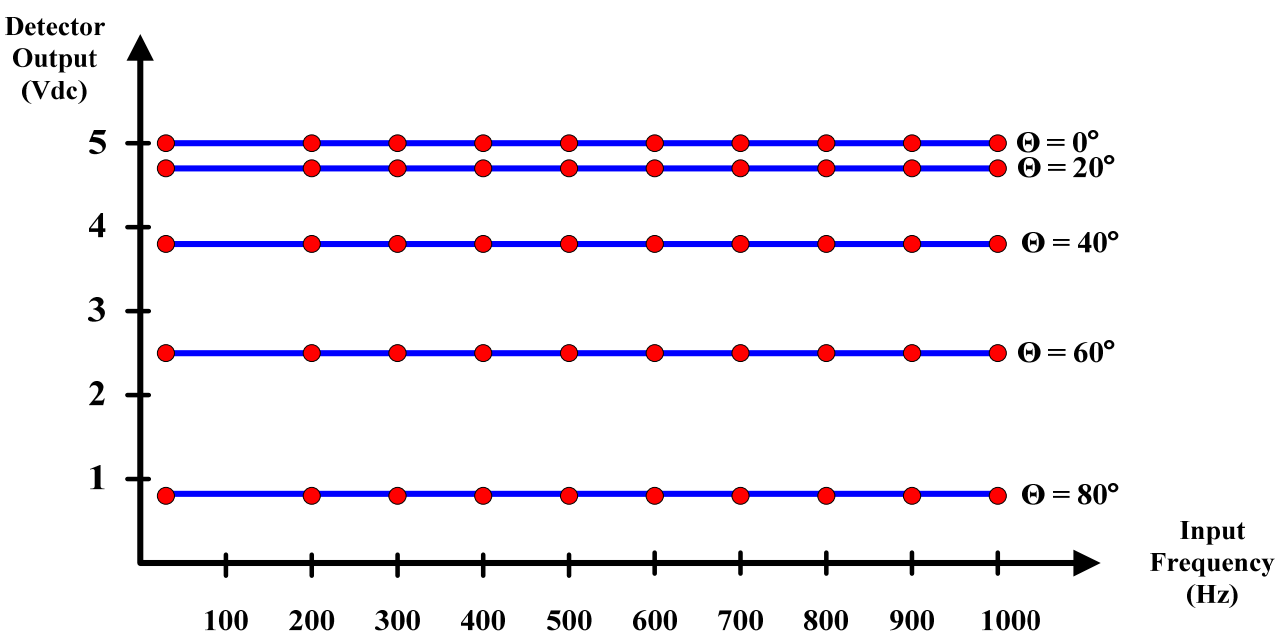

Figure 5. The performance of the detector under variable frequency 


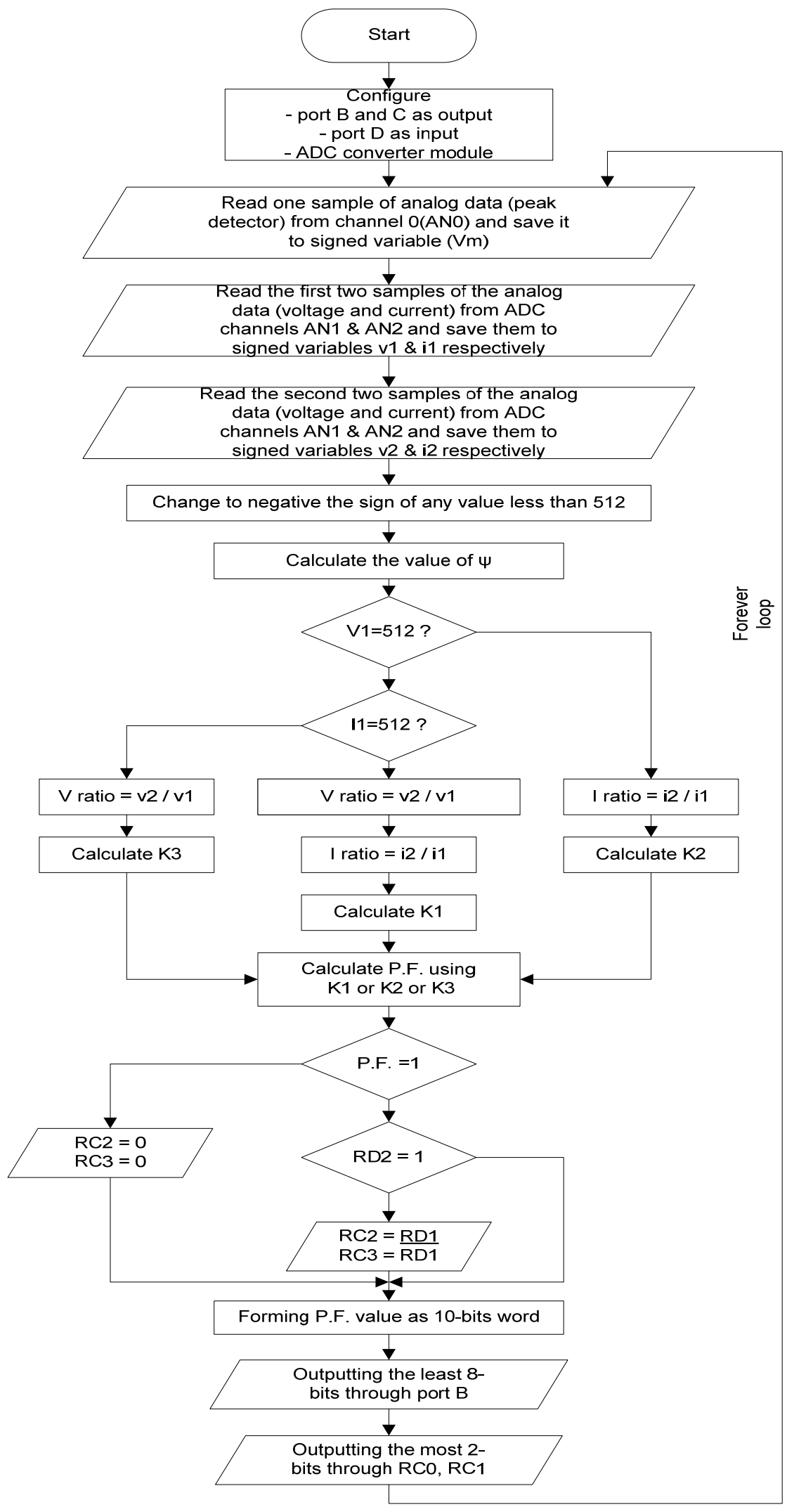

Figure 4. System flowchart 


\section{CONCLUSION}

A new ultra fast frequency independent instantaneous power factor detector is described. The proposed detector required two progressive samples of the voltage and current separated by random short time. The proposed method is implemented based on microcontroller with few support circuits. The high-frequency limit is determined mainly by the maximum sampling frequency of the ADC. The developed detector is highly reliable and possesses enough flexibility to suit the requirement of frequency-variant systems.

\section{REFERENCES}

[1] D.H. Boghasian and M.H.A. Abdul Kareem, "A digital power factor meter design based on BRM techniques, " IEEE Trans.IM, vol. 29, no. 4, pp. 435-438, Jan 1981.

[2] M.S.M. Al Any and M.A.H. Abdul-Kareem, "A digital power factor meter design," International Journal of Electronics, vol. 57, no. 3, pp. 439-444, 1984.

[3] B. Hafidh and M.A.H. Abdul-Kareem, "Digital power factor meter based on nonlinear ADC conversion, " International Journal of Electronics, vol. 57, no. 3, pp. 513-519, 1985.

[4] S.M.R. Taha and M.A.H. Abdul Kareem, "A novel digital power factor meter design," IEEE Transaction on IM, vol. 35, no. 4, pp. 638-640, Dec. 1986.

[5] M. A. Shree and D. P. Vadana, "Smart meter for power factor in real-time," International Conference on Embedded Systems (ICES), pp. 177-181, 2014

[6] S. Farhat and E. Cohen, "A digital power factor meter based on ratio metric ADC," Journal of Physics and Scientific Instruments, vol. 21, no. 9, pp. 848-850, 1988.

[7] N. Bakos, K. Abdulkareem and M. AlTikriti, "phase shift power factor measurement for a wide frequency range using ROM," Int. Journal of Electronics, vol. 64, no. 2, pp. 299-304, 1988.

[8] C. Prasauna, S. Sabberwal and A. Mukherji, "power factor measurement and correction techniques," Electric power systems research, vol. 32, no. 2, pp. 141-143, 1995.

[9] L.Y. Zhou, Z.D. Yin, X.N. Xiao, Z.Q. Wang and L. Zheng, "study on power factor through the similarity of waveforms," $3^{\text {rd }}$ IEEE conference on Industrial Electronics and Applications, pp. 1534-1537, 2008.

[10] H. Das and L. C. Saikia, "Ethernet based smart energy meter for power quality monitoring and enhancement," Recent Developments in Control, Automation \& Power Engineering (RDCAPE), pp. 187-191, 2017.

[11] E So, P. N. Miljanic, and D. Angelo, "A computer-controlled load loss standard for calibrating high-voltage power measurement systems," IEEE Trans. Instrum. Meas., vol. 44, pp. 425-428, 1995.

[12] J. C. Wu and H. L Jou, "Fast Response Power Factor Detector," IEEE Transaction on Instrumentation \& Measurement, Vol. 44, No. 4, pp. 919-922, 1995.

[13] S.S. Omran and A.S. Alkhalid, "A novel digital power factor meter," Al Buhooth al Taqaniya, no. 67, pp. 54-62, 2000.

[14] D. R. Tutakne, H.M. Suryawanshi, T.G. Arora, M. Mishra and S.G. Tarnckar, " Single-Phase Fast Response Power Factor Transducer," proceedings of IEEE ISIE, Montreal, Quebec, Canada, pp. 1765-1768, 2006.

[15] S.S. Omran and Ali. Sh. Al-Khalid, " A Microprocessor - Based Fast Power Factor Meter," Al-Buhooth Al_Taqunya, no. 102, pp. 60-65, 2002.

[16] S.. $\bar{S}$. Omran, Ali. Sh. Al-Khalid and J.A. Kadum, " A Novel and Fast Power Factor Calculation Method," Al-Buhooth Al_Taqunya, vol. 17, no. 6, pp. 25-30, 2004.

[17] A. S. Al-Khalid and Safaa. S. Omran, "A Very Fast Power Factor Calculation Method," proceedings of IEEE Symposium on Industrial Electronic and Applications, Langkawi, Malaysia, pp. 494-497, 2011.

[18] K. A. Hameed, "A microcontroller based digital power factor and phase angle meter," Journal of Electrical \& Electronics Engineering IOSR-JEEE, vol. 11, issue 1, pp. 82-86, 2016.

[19] P. P. Machado, T.P. Abud, M.Z. Fortes and B.S. Barba, "power factor metering system using Arduino, " IEEE workshop in power electronics and power quality Applications (PEPQA), PP. 1-6, 2017.

[20] A. A. Yaseen, "Fast-Response Power Factor Computation Technique," proceedings of IEEE of the $2^{\text {nd }}$ International Conference on Advances in Computational Tools for Engineering Applications (ACTEA), Beirut, Lebanon, pp. 235-240, 2012.

[21] S. Wang and C. Wu, "Design of an accurate power factor measurement approach using FPGA based chip, "Wseas Transactions on Circuits and Systems, vol. 9, no. 7, pp. 453-462, 2010.

[22] A. Biswas, S. Dhar, A. Kumar and A. Sanyal, "power factor measurement and correction using digital controller implementation in FPGA," Int. Journal of microelectronics engineering (IJME), vol. 1, no. 1, pp. 25-34, 2015.

[23] A. Biswas, S. Dhar, A. K. Basu, and A. Sanyal, "Power Factor Measurement and Correction using Digital Controller Implemented on FPGA" International Journal of Microelectronics Engineering (IJME), vol. 1, no.1, pp. 25-34, 2015. 


\section{BIOGRAPHIES OF AUTHORS}

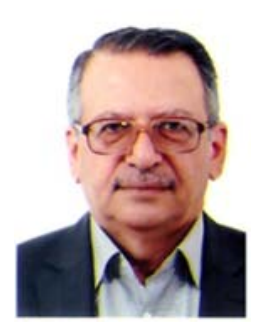

Safaa S Omran was born in Iraq. I graduated from University of Baghdad in 1978, and then I got the MSc from the same University in 1984. Now I am working in the Electrical Engineering College / Middle Technical University as an assistant prof. My interest working researches in the field of microprocessor design for embedded systems, Image processing and cryptography system design.

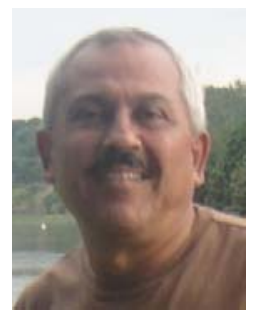

Ali S Alkhalid was born in Baghdad, Iraq in 1958. He received his BSc and MSc in electrical engineering in 1980 and 1983 respectively from the University of Baghdad. He is now an assistant professor working at the College of Electrical Engineering Technical College, the middle technical university, Baghdad, Iraq. His main interest is in instrumentation and measurement in power line. He is also interested in the field of cryptanalysis.

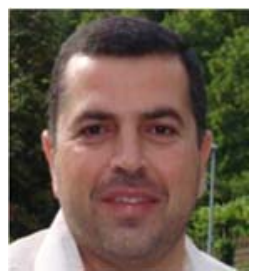

Amer Atta Yaseen received his BSc in Electrical Engineering (1998) from Al-Mustansiriya University and MSc in Control and Automation Engineering (2005) from University of Technology, Baghdad, Iraq. He is now a Lecturer in Medical instruments engineering department, Electrical Engineering Technical College, Middle Technical University. Baghdad, Iraq. His interest in Microcontroller Programming using mikroC and assembly language and control applications. 